\title{
Survey on the Awareness of Health Impact of the Proliferation of Telecommunication Base Transmitter Stations in Kaduna, Nigeria
}

\author{
Celestine Ozoemenam Uwa ${ }^{1}$, Francisca Nonyelum Ogwueleka ${ }^{2}$, Abdullahi Yusuf Egwoh ${ }^{3}$, \\ and Darius Tienhua Chinyio ${ }^{4}$ \\ Lecturer, Computer Science Department, Nigerian Defence Academy, Kaduna, Nigeria ${ }^{1,4}$ \\ Professor, Computer Science Department, Nigerian Defence Academy, Kaduna, Nigeria ${ }^{2}$ \\ PhD Student, Computer Science Department, Nigerian Defence Academy, Kaduna, Nigeria ${ }^{3}$
}

\begin{abstract}
With the growth in mobile phone use, there has been inevitable increase and proliferation of mobile phone Base Transceiver Stations (BTS), accompanied by public concern for possible health impacts associated with exposure to Electromagnetic Waves (EMW) emanating from BTS. This survey was carried out to determine the awareness of inhabitants about the health problems associated with GSM Base Transceiver Stations (BTS) due to the exposure of people to EMW. The study area covers selected BTS in Buwaya, Gonin Gora and Maraba Rido in Chikun local government area; and Kakuri in Kaduna south local government area. These sample areas were selected due to the high population density. A sample size of 400 was selected randomly based on the literacy level of the respondents. Data was collected from respondents through structured questionnaire. The data collected was analysed using tables of frequency and percentages, and bar charts. A test of statistic was conducted with Chi Square test. The results showed that about 78.5\% have no knowledge of electromagnetic radiation and its consequences on human health; and the Chi Square test based on the respondent's duration of living near BTS showed that EMR affects human health. However, no medical tests were carried out to confirm the claims by respondents and the result of the study was based on what the respondents reported.
\end{abstract}

Keywords: Base Transceiver Station or Base Transmitter Station (BTS), Electromagnetic Radiation (EMR), Electromagnetic Wave (EMW), Global System of Mobile Telecommunication (GSM), Antenna, Radio Signals.

\section{INTRODUCTION}

The world has witnessed rapid growth of mobile phones use over the past few decades. Worldwide in 2013, there were 6.8 billion mobile phone subscribers which are almost as many people on earth (Mohammed, 2014; ITU, 2013). Similarly, the use of mobile phone which was introduced in Nigeria in August 2001 has increased tremendously over the past few years with the total number of mobile phone active subscribers reaching about 40 million as at the end of December 2016. With this growth in mobile phone use there has been inevitable increase in the number of mobile phone Base Transceiver Stations (BTS), accompanied by public concern for possible health impacts associated with exposure to Electromagnetic Waves (EMW) emanating from BTS (Mohammed, 2014; ITU, 2013).

Base Transmitter Stations (BTS) are radio transmitters mounted on either free-standing masts or on buildings that facilitate wireless communication between user equipment and a network. The base station antennas serving macro cells are either mounted on free-standing towers, typically 10-30 m high or short towers on top of buildings, or attached to the side of buildings. In a typical arrangement, each tower supports three antennas, each transmitting into a $120^{\circ}$ sector. The main beam is tilted slightly downwards but does not reach ground level until the distance from the tower is at least $50 \mathrm{~m}$ (usually 50-200 m). Radio signals are fed through cables to the antennas and then launched as radio waves into the area or cell, around the BTS (Neubauer et al, 2003). At positions where people are exposed to the radio waves from BTS, the level of exposure is much more constant over whole body than when they are exposed to a mobile phone (Stewart, 2000).

\section{RELATED LITERATURE}

A survey by the World Health Organization showed Radio Frequency (RF) exposure from BTS range from $0.002 \%$ to $0.2 \%$ of the levels of international exposure guidelines depending on the proximity to the antenna and other surrounding environmental factors (Mohammed, 2014; WHO, 2014). This is low or comparable to RF exposure from radio or television broadcast transmitters and the temperature increase is insignificant and results in no adverse health effect. 


\title{
International Journal of Advanced Research in Computer and Communication Engineering
}

\author{
Vol. 9, Issue 9, September 2020
}

\section{DOI 10.17148/IJARCCE.2020.9904}

Consequently, the strength of the RF field is greatest at the source and diminishes quickly with distance (Mohammed, 2014; ICNRP, 2009). Access near base station antennas is often restricted where RF signal may exceed international exposure limits. Previous studies have reported that RF exposure might be associated with several adverse health effects and complaints such as cancers in children, headache, neurological changes, loss of memory, increased blood pressure, and damage to eye cells (Otto \& Mühlendahl, 2007; Zwamborn et al, 2003; Elliott et al, 2010). Howe ver, most of these studies did not find a direct association between RF exposure and health complaints in the study population, rather a concern for the RF exposure might be responsible for the reported health effects (Preece et al, 2005). In addition, the se symptoms are often not independent of each other and demand further evaluation (Blettner et al, 2009).

At its launch, there were only two operators in Kaduna, MTN and Econet which metamorphosed to Vmobile, Zain and now Airtel. Today, there are several operators across the nation; among the existing ones in Kaduna metropolis include 9Mobile, Globacom, Startcomms, Visafone, Airtel and MTN. With the ever increasing number of mobile phone users in Kaduna metropolis and indeed all other urban cities in Nigeria, more and more BTS are being erected to support the network growth in different public areas in the city. It was estimated that, more than 120 masts are built monthly on the average by the service providers nationwide and as at today, there are about 8,600 masts in Kaduna (Mohammed, 2014). It has become a part of the environment to see tall masts in different locations around the country. These masts though helpful, are believed to have negative health effects on people living near where they are erected. It is argued that telecom towers interfere with aircrafts approaching landing and feared that towers could fall on people and property. The erection of masts clustered in built-up areas are thus said to be hazardous (Osaretin, 2011).

Mobile phone base stations and telecommunications towers emit radiofrequencies (RF), a form of electromagnetic radiation (EMR) for a distance of up to 2 miles (322 metres). There are claims that these electromagnetic radiations are injurious to health and the environment. Some have dismissed such claims because the radio frequency (RF) and electromagnetic energy (EME) exposure levels produced by these facilities are said to be weak and that the level of emissions from cellular infrastructure is lower than emissions from some household appliances like microwave ovens and televisions (Ogboru, 2015). In contrast to mobile handsets, radiation is emitted continuously from BTS and is more powerful at close quarters (Mohammed, 2014). Despite public concern about the safety of mobile phones and BTS, there is no published literature on the possible health effects of BTS in Nigeria. One is at a loss as to how the two government agencies, Nigerian Communications Commission (NCC) and National Environmental Standards and Regulations Enforcement Agency (NESREA), purporting to be following international standards and specifications for the siting of telecom towers and base stations arrived at different set back distances in their Regulations. While NESREA is having 10 metres set back distance provided for in its regulation, NCC's regulation of 5 metres set back distance from the houses is stipulated (Ogboru, 2015).

According to Osaretin (2011), it was clear that the mobile operators did not obtain the necessary Environmental Impact Assessment before erecting those masts. In addition to non-compliance with environmental certification, tests carried out at the site showed that the noise level was very high compared to what should be obtainable in a residential area. The mast also violated the regulation on the distance between a telecommunication mast and a residential building, as well as the distance from the road. A survey study by Santini et al (2002) in France found a variety of self-reported symptoms for people who reported that they were living within 300 metres (984 ft) of GSM cell towers in rural areas, or within 100 metres $(328 \mathrm{ft}$ ) of base stations in urban areas. Fatigue, headache, sleep disruption and loss of memory were among the symptoms reported. Similar results have been obtained with GSM cell towers in Spain, Egypt, Poland and Austria. No major studies have been reported in which health effects did not occur on actual populations living near mobile base stations (Osaretin, 2011). From epidemiologic research, persons living in places where telecommunication masts are erected are vulnerable to disorders like cancer, lung diseases, sleep disturbances and even physical disabilities; though according to WHO research, there are no current scientific proofs of health hazards associated with telecommunication masts (Osaretin, 2011).

There were complaints about the hazardous effects of the base stations on the health of people living close to the masts and BTS. They complained about fatigue, headache and sleep disruption. There were also complaints about noise, vibrations and fumes from standby power generators at the telecom base stations and the likelihood of causing damage to property (Osaretin, 2011). The effects of mast on city dwellers can be complex. There are silent long term problems that may affect the resident health. In United States for instance, masts have been associated with cancer and other grave illnesses. Occurrence like fatigue, headache, decreased concentration, dizziness, local irritation, tumour induction, sperm motility, morphology and viability, cancer, especially brain tumour and leukaemia, viral and infectious diseases has been blamed on living within 1-5 km distance from masts in Dunganon (Abdel et al, 2007).

There are concerns, nevertheless, about whether the emissions from all BTS are uniformly low, about whether the emissions could cause unknown health effects, and whether, with the increased use of mobile telecommunications, their output will have to rise (Ahlbom et al, 2004). The International Agency for Research on Cancer showed that extremely low-frequency magnetic fields are possibly carcinogenic to humans (IARC, 2002). EMF was demonstrated as a possible cause for the following health outcomes by the California EMF-Program 2002: leukaemia in children and adults, brain tumour in adults, miscarriage among pregnant mothers, and motor neuron disease (MND) (Neutra et al, 2002; Mild, 2008; Inskip et al, 2001; Deltour et al, 2012; Schüz et al, 2006). Although several risk factors have been investigated, 


\title{
International Journal of Advanced Research in Computer and Communication Engineering
}

\author{
Vol. 9, Issue 9, September 2020
}

\section{DOI 10.17148/IJARCCE.2020.9904}

most studies on exposure from BTS could not find a direct association between RF-EMF and health complaints but several studies found health complaints associated with concern about RF-BTS. In addition, standardized blinded experimental studies were not able to confirm associations between EMF exposure and the physical complaints of the respondents (Mohammed, 2014).

\section{METHODOLOGY}

\section{A. Study Area}

The study was conducted in Chikun and Kaduna South Local Government Areas of Kaduna State for 6 weeks, from October 2, 2017 to November 13, 2017. Samples were drawn from the following areas in Chikun Local Government Area: Buwaya, Gonin Gora, and Maraba Rido. In Kaduna South Local Government Area, samples were drawn from Kakuri. A total of 35 BTS were selected and samples of 400 adults from 18 years and above were used for the study. However, only 325 questionnaires were returned. 28 BTS were selected out of 40 in the selected area of Chikun Local Government Area and 7 BTS out of 10 BTS in Kakuri area of Kaduna South Local Government Area. Participants who were used for the survey were mainly those who have BTS erected within their living compounds and those whose house are located very close to these BTS. Both male and female adults who showed interest in the survey were used and a number of people declined to participate. Also, in the selection of the study population consideration was given to people who have been living in these areas for at least 12 months.

\section{B. Data Collection}

Before data were collected, participants were informed about the objective of the study and were assured of adequate protection/confidentiality of information volunteered, their anonymity, and that their participation was purely on voluntary basis. Data were gathered from the target population through the use of structured questionnaire. The selection of the sample was based on the literacy level of the participants. Only those who showed the capability of reading and writing were selected. The structured questionnaire was designed to gather information on the following areas: period of living in the current residence, proximity of BTS to living residence, demographic information, knowledge and awareness of health implications of BTS and EMW, self-reported health problems like shivering, convulsion, sleeping disorders, skin problems, incidence of miscarriage/pregnancy related issues, infertility related problems, abnormality in infants, burning sensation, headaches, dizziness, depression, general body weakness, mental health, cardiovascular diseases (CVD), gastrointestinal symptoms (GIT), loss of hearing, eye defects, sexual weakness and noise in the environment.

\section{Research Questions/Hypothesis}

The survey sought answers to the following research questions.

a. Is the respondent aware that EMR is being generated from BTS?

b. Does the respondent agree that EMR affects human health?

The following hypothesis was set up to answer the research questions.

$\mathrm{H}_{0}$ : $\quad$ EMR does not affect human health.

$\mathrm{H}_{1}$ : $\quad$ EMR affects human health.

\section{DATA ANALYSIS AND TESTING}

When data collection was concluded, it was checked to eliminate errors. Thus, data items which did not naturally belong to the set were eliminated and inconsistences were removed. Tables of frequency and their associated percentages were prepared to show the findings. Chi Square test was carried out on the data collected and some results were presented in bar charts.

\section{A. Demographic Characteristics}

Data was collected from 325 respondents who are residing very close to BTS. Out of the total of 325 respondents, 160 representing $49.2 \%$ are males and the rest, 165 representing 50.8 percent are females. There are 100 respondents representing $30.8 \%$ belonging to the age group of 18 to 30 years, 128 respondents representing $39.4 \%$ belonging to the age group 31 to 43 years while 97 respondents representing $29.8 \%$ belong to the age group 40 years and above. $50.8 \%$ of the respondents are said to be living in their current residence for 12 to 48 months, $38.4 \%$ have been living in their current residence for 49 to 85 months and $10.8 \%$ have lived for more than 85 months in their current residence. Table I gives the information on the demographic characteristics of the 325 respondents based on their sex, age class and duration of living in current residence. 


\section{International Journal of Advanced Research in Computer and Communication Engineering}

Vol. 9, Issue 9, September 2020

DOI 10.17148/IJARCCE.2020.9904

Table I Demographic characteristics of the respondents $(\mathrm{n}=325)$

\begin{tabular}{|c|c|c|}
\hline Variable & Number & Percentage \\
\hline Male & 160 & 49.2 \\
\hline Female & 165 & 50.8 \\
\hline Age group (years) & & \\
\hline $18-30$ & 100 & 30.8 \\
\hline $31-43$ & 128 & 39.4 \\
\hline $44-$ Above & 97 & 29.8 \\
\hline Duration of living in & Current residence & (months) \\
\hline $12-48$ & 165 & 50.8 \\
\hline $49-85$ & 125 & 38.4 \\
\hline 86 above & 35 & 10.8 \\
\hline
\end{tabular}

Figure 1 is the bar chart of responses according to duration of living in current residence. The chart shows that more female respondents have lived between 12-48 months in their current residence while more males have lived for 49-85 months in their current residence.

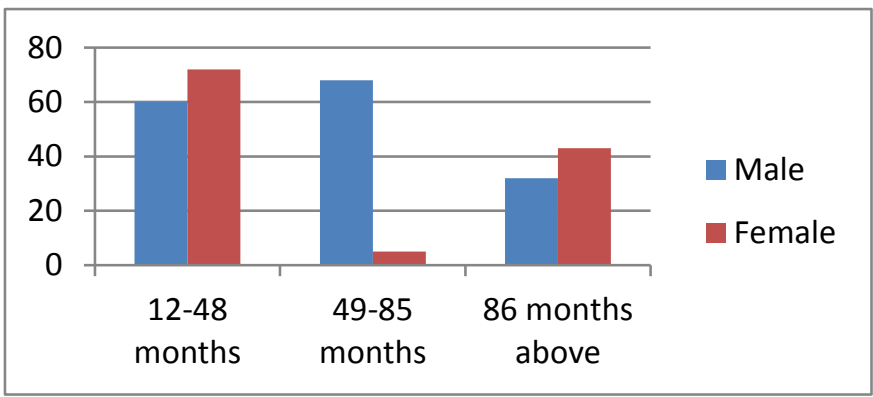

Figure 1: Responses according to duration of living in current residence

\section{B. Knowledge and awareness of BTS and EMR according to area of residence.}

It was discovered that $96.3 \%$ of the respondents reported to have seen BTS while $63.1 \%$ agreed that they have seen at a close range parts of BTS. However, only $17.5 \%$ of the respondents accepted to have known how BTS works and the majority of the respondents, $78.5 \%$ have no knowledge about EMR and its adverse effects on human health. These results are shown in Table II.

Table II Knowledge and awareness of BTS and EMR according to area of residence

\begin{tabular}{|l|l|l|l|l|l|l|}
\hline & Buwaya & Gonin Gora & Maraba Rido & Kakuri & Total number & Percentage \\
\hline Seen BTS & 80 & 93 & 75 & 65 & 313 & 96.3 \\
\hline Seen parts of BTS & 45 & 70 & 50 & 40 & 205 & 63.1 \\
\hline Know how BTS works & 13 & 18 & 15 & 11 & 57 & 17.5 \\
\hline Knowledge of EMR & 20 & 15 & 14 & 21 & 70 & 21.5 \\
\hline
\end{tabular}

Figure 2 represents the responses about the knowledge and awareness of BTS and EMR from the sample population. The figure indicates that more respondents from Gonin Gora has seen both BTS and parts of BTS. However, slightly more respondents from Kakuri have knowledge of EMR.

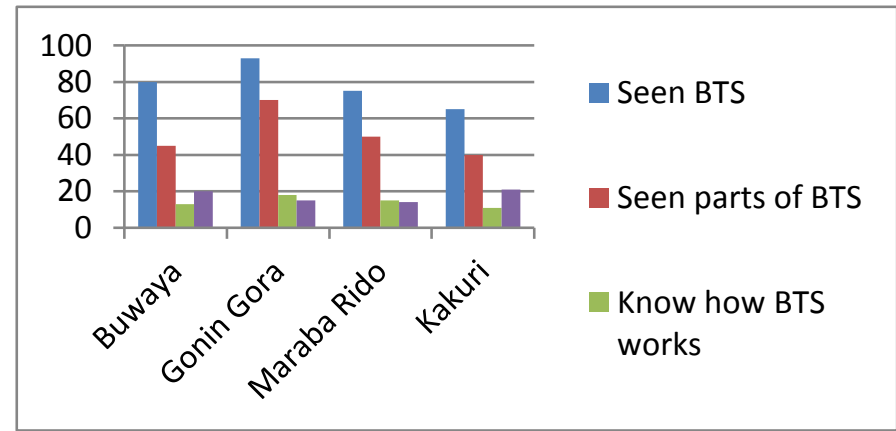

Figure 2 Knowledge and awareness of BTS and EMR according to area of residence 


\title{
International Journal of Advanced Research in Computer and Communication Engineering
}

\author{
Vol. 9, Issue 9, September 2020
}

DOI 10.17148/IJARCCE.2020.9904

\section{Perceived effects of EMR}

The respondents' reactions with respect to our hypothesis are given in Tables III and IV. Table III shows the responses based on sex. It was discovered that $47 \%$ of the male respondents supported the alternative hypothesis $\left(\mathrm{H}_{1}\right)$, $37 \%$ was against and $16 \%$ remained indifferent. On the other hand, $41 \%$ of the female respondents were in support of the alternative hypothesis, $37 \%$ was against and $22 \%$ were neither in support nor against. With respect to age class of respondents, $40 \%$ of the age class 18-30 was in support, $37 \%$ was against and $23 \%$ remained indifferent. $45 \%$ of the age class, $31-43$ was in support of the alternative hypothesis, $39 \%$ was against and $16 \%$ had no responses. The age class 44 years and above, had $43 \%$ in support, $38 \%$ against and $19 \%$ did not support any of the hypothesis.

Table III Responses according to Sex

\begin{tabular}{|l|l|l|l|}
\hline Sex & Yes & No & No response \\
\hline Male & 75 & 60 & 25 \\
\hline Female & 68 & 60 & 37 \\
\hline
\end{tabular}

Figure 3 shows the respondents responses according to sex. It shows that more males supported the alternative hypothesis while there were more females who were indifferent.

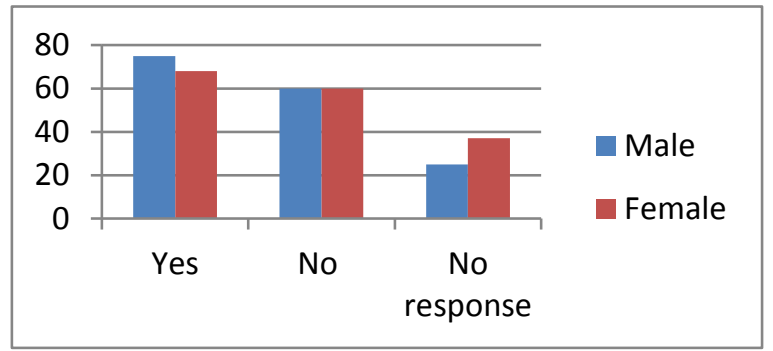

Figure 3: Bar chart representing responses according to Sex

Table IV represents respondents' responses according to Age class. It is observed that 40 respondents in the Age class of 18-30 supported the motion that Electromagnetic Radiation affects human health, 57 in the Age class 31-43 was in support also and 42 in the Age class of 44 years and above was equally in support.

Table IV Response according to Age class

\begin{tabular}{|l|l|l|l|}
\hline Age class & Yes & No & No response \\
\hline $18-30$ & 40 & 37 & 23 \\
\hline $31-43$ & 57 & 50 & 21 \\
\hline 44 above & 42 & 37 & 18 \\
\hline
\end{tabular}

Figure 4 is the bar chart representing responses based on Age class. Figure 4 shows that $40 \%$ of the respondents in the age class of 18-30 supported the alternative hypothesis that EMR affects human health. On the other hand, 39\% of the respondent in the age class 31-43 supported the null hypothesis that EMR does not affect human health and $19 \%$ of the respondents in the age class 44 years and above neither supported the null hypothesis nor the alternative hypothesis.

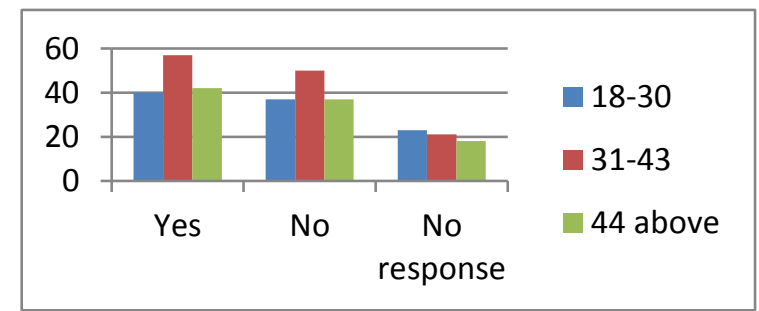

Figure 4: Responses based on age class of respondents

\section{Analysis by Chi Squared Tests}

From the results obtained from the Chi squared test, based on the respondent' age class, the value of 0.199 is greater than our significant level of 0.05 , this means that EMR affects human health and therefore, we reject the null hypothesis, $\mathrm{H}_{\mathrm{o}}$, EMR does not affect human health and accept the alternative hypothesis, $\mathrm{H}_{1}$, EMR affects human health. Also, the Chi squared test performed with respect to respondents' sex showed that the value of $0.5>0.05$ level of significance which 
supported the alternative hypothesis and the earlier result. In addition, Chi Squared test was carried out based on the respondents' duration of living in their current residences. In this case, a value of 0.5 was obtained and since $0.5>0.05$, we reject $\mathrm{H}_{\mathrm{o}}$ and accept $\mathrm{H}_{1}$ which corroborated our earlier results. Hence, we conclude that EMR affects human health. Table V shows the Chi Squared test based on the respondent' age class. From the table, the Chi Squared value of 0.199 is greater than the 0.05 level of significance leading to the rejection of the null hypothesis.

Table V Chi squared table based on the respondents' age class

\begin{tabular}{|l|l|l|l|}
\hline & Value & Df & Asymptotic Significance (2-sided) \\
\hline Pearson Chi-Square & $6.000^{\mathrm{a}}$ & 4 & .199 \\
Likelihood Ratio & 6.592 & 4 & .159 \\
Linear-by-Linear Association & 1.913 & 1 & .167 \\
N of Valid Cases & 3 & & \\
\hline
\end{tabular}

Table VI shows the Chi Squared test based on the respondents' sex and a value of 0.5 was obtained. When compared to 0.05 , the alternative hypothesis was accepted.

Table VI Chi Squared table based on the respondents' sex

\begin{tabular}{|c|c|c|c|c|c|}
\hline & Value & Df & $\begin{array}{l}\text { Asymptotic } \\
\text { Significance (2-sided) }\end{array}$ & Exact Sig. (2-sided) & Exact Sig. (1-sided) \\
\hline $\begin{array}{l}\text { Pearson Chi-Square } \\
\text { Continuity Correction }{ }^{\mathrm{b}} \\
\text { Likelihood Ratio } \\
\text { Fisher's Exact Test } \\
\text { Linear-by-Linear Association } \\
\mathrm{N} \text { of Valid Cases }\end{array}$ & $\begin{array}{l}2.000^{\mathrm{a}} \\
.000 \\
2.773 \\
1.000 \\
2\end{array}$ & $\begin{array}{l}1 \\
1 \\
1 \\
1\end{array}$ & $\begin{array}{l}.157 \\
1.000 \\
.096 \\
.317\end{array}$ & 1.000 & .500 \\
\hline
\end{tabular}

Table VII shows the Chi Squared test based on the respondents' duration of living in current residence and a value of 0.5 was obtained. When compared to 0.05 , we reject the null hypothesis, EMR does not affect human health and accept the alternative hypothesis, EMR affects human health.

Table VII Chi Squared table based on the respondent' duration of living in current residence

\begin{tabular}{|c|c|c|c|c|c|}
\hline & Value & Df & $\begin{array}{l}\text { Asymptotic } \\
\text { Significance (2-sided) }\end{array}$ & $\begin{array}{lll}\text { Exact } & \text { Sig. } & \text { (2- } \\
\text { sided) } & & \\
\end{array}$ & $\begin{array}{lll}\text { Exact } & \text { Sig. } \\
\text { sided }) & & \\
\end{array}$ \\
\hline $\begin{array}{l}\text { Pearson Chi-Square } \\
\text { Continuity Correction }{ }^{\mathrm{b}} \\
\text { Likelihood Ratio } \\
\text { Fisher's Exact Test } \\
\text { Linear-by-Linear Association } \\
\mathrm{N} \text { of Valid Cases }\end{array}$ & $\begin{array}{l}2.000^{\mathrm{a}} \\
.000 \\
2.773 \\
1.000 \\
2\end{array}$ & $\begin{array}{l}1 \\
1 \\
1 \\
1\end{array}$ & $\begin{array}{l}.157 \\
1.000 \\
.096 \\
.317\end{array}$ & 1.000 & .500 \\
\hline
\end{tabular}

\section{CONCLUSION}

The results show that most of the respondents have seen BTS from far and near distances but are not familiar with how BTS works. The results equally showed that there are low level of awareness of EMR and its health consequences. From the study, it was discovered that $96.3 \%$ of the respondents have seen BTS, $63.1 \%$ of them reported to have seen parts of BTS on a close range, $82.5 \%$ of the respondents do not know how BTS works and $78.5 \%$ have no knowledge about EMR and its consequences on human health. The study equally showed that EMR affects the lives of the citizenry especially those living near BTS. However, we cannot conclude that the health effects as reported by the respondents has direct bearing to exposure to BTS as most of these respondents are exposed on a daily bases to EMR from other sources such as house hold appliances like microwave oven which is said to have higher level of EMR than that of BTS. In addition, since previous medical history of these respondents were not taken into consideration and an appropriate sample size involving a control group was not used, this result is not too significant to cause fear and panic among the people living near BTS. 


\title{
International Journal of Advanced Research in Computer and Communication Engineering
}

\author{
Vol. 9, Issue 9, September 2020
}

\section{DOI 10.17148/IJARCCE.2020.9904}

\section{REFERENCES}

[1]. R. Abdel, G. Batanouny and E. Salem, Neuro behavioural effects among inhabitants around mobile phone base stations. International Journal of Hygiene and Environmental Health, 2007, vol. 207, no. 3, p. 245-254.

[2]. A. G. Ahlbom, L. Kheifets, D. Savitz and A. Swerdlow, Epidemiology of health effects of radiofrequency exposure. Environmental Health Perspectives, 2004, vol. 112, no. 17, p 174-175.

[3]. M. Blettner, B. Schlehofer and J. Breckenkamp, Mobile phone base stations and adverse health effects: phase 1 of a population-based, crosssectional study in Germany. Occupational and Environmental Medicine, 2009, vol. 66, no. 2, p. 118-123.

[4]. I. Deltour, A. Auvinen and M. Feychting, Mobile phone use and incidence of glioma in the nordic countries 1979-2008: consistency check. Epidemiology, 2012, vol. 23, no. 2, p. 301-307.

[5]. P. Elliott, M. B. Toledano and J. Bennett, Mobile phone base stations and early childhood cancers: case-control study. British Medical Journal, 2010, vol. 340 , no. 3 , p. 307.

[6]. IARC Working Group on the Evaluation of Carcinogenic Risks to Humans, Non-ionizing radiation, Part 1: static and extremely low-frequency (ELF) electric and magnetic fields. IARC Monographs on the Evaluation of Carcinogenic Risks to Humans/World Health Organization, International Agency for Research on Cancer, 2002, vol. 80, p. 1-395.

[7]. ICNRP (International Commission on Non-Ionizing Radiation Protection), Guidelines on limits of exposure to static magnetic fields. Health Physics, 2009, p. 504-514.

[8]. P.D.Inskip, R.E.Tarone and E.E. Hatch, Cellular-telephone use \& brain tumours. New England Jourl of Medicine, 2001 , vol. 344 , no. 2 , p 79-86.

[9]. ITU (International Telecommunication Union), The World in 2013 ICT Facts and Figures. International Telecommunication Union, Geneva, Switzerland, 2013, vol. 45, no. 3, p. 67-87.

[10]. H. Mild, Meta-analysis of long-term mobile phone use and the association with brain tumours, International Journal of Oncology, 2008, vol. 32, no. 5, p. 1097-1103.

[11]. S. I. Mohammed, Awareness and Self-Reported Health Hazards of Electromagnetic Waves from Mobile Phone Towers in Dhaka, Bangladesh: A Pilot Study. Advances in Public Health, 2014, vol. 1, p. 1-7.

[12]. G. Neubauer, H. Haider and K. Lameds, Measurement methods and legal requirements for exposure assessment next to GSM base stations. Proceedings of the 15th International Zurich Symposium on Electromagnetic Compatibility, 2003.

[13]. R. Neutra, V. D. Pizzo and G. M. Lee, An evaluation of the possible risks from Electric and Magnetic Fields (EMF) from power lines, internal wiring, electrical occupations, and appliances. California EMF Program - Final Report, 2002.

[14]. T. Ogboru, NESREA AND NCC Regulations on telecommunication masts: Implementing the precautionary principle. Journal of sustainable development, law and policy, 2015, vol.5, no. 1, p. 55-70.

[15]. A. Osaretin, Health Implications of telecommunication mast. Environmental Health Experience, 2011. Available: https://www.tigweb.org/youthmedia/panorama/article.html?ContentID=31421

[16]. M. Otto and K. E. Mühlendahl, Electromagnetic fields (EMF): do they play a role in children's environmental health (CEH)?. International Journal of Hygiene and Environmental Health, 2007, vol. 210, no. 5, p.635-644.

[17]. A. W. Preece, S. Goodfellow and M. G. Wright, Effect of $902 \mathrm{MHz}$ mobile phone transmission on cognitive function in children. Bio electromagnetics, 2005, vol. 26, no. 7, p. S138-S143.

[18]. R. Santini, P. Santini, J. M. Danze, P. Le Ruz and M. Seigne, Investigation on the health of people living near mobile telephone relay stations: I/Incidence according to distance and sex. Pathologie-Biologie, 2002, vol. 50, no. 6, p. 369-373.

[19]. J. Schüz, E. Böhler and G. Berg, Cellular phones, cordless phones, and the risks of glioma and meningioma (Interphone Study Group, Germany). The American Journal of Epidemiology, 2006, vol. 163, no. 6, p. 512-520.

[20]. S. W. Stewart, Independent Expert Group on Mobile Phones. Mobile phones and health, 2000. Available:https://www.mobile-phones+and+health \&author=independent+expert+group+mobile+phones\& publication_year=2000.

[21]. WHO (World Health Organization), Electromagnetic Fields and Public Health, 2014. Available: http://www.who.int/pehemf/publications/facts/fs296/en/.

[22]. A. P. M. Zwamborn, S. H. J. Vossen, B. J. A. Leersum, M. A. Ouwens and W. N. Makel, Effects of global communication system radio-frequency fields on well-being and cognitive functions of human subjects with and without subjective complaints. TNO-Report FEL-03-C148, 2003. 